\title{
O uso da terra nas áreas de preservação permanente (APP) do curso médio do rio Paranapanema e suas implicações na qualidade microbiológica da areia destinada à construção civil em Ourinhos (SP)
}

The land use in the permanent preservation areas (PPA) of Paranapanema river's medium course and their implications in the microbiological quality of the sand intended to the civil at Ourinhos (SP), Brazil

\author{
Angélica Scheffer da Motta Abrantes ${ }^{a}$ \\ Maria Cristina Perusi ${ }^{b}$
}
a Mestranda do Programa de Pós-Graduação em Geografia da Universidade Estadual Paulista "Júlio de Mesquita Filho" (Unesp) - Campus de Presidente Prudente.
E-mail: angelica_scheffer@hotmail.com
b Docente do curso de Geografia da Universidade Estadual Paulista "Júlio de Mesquita Filho"
(Unesp) - Campus de Ourinhos.
E-mail: cristina@ourinhos.unesp.br

\begin{abstract}
Em muitas residências de alvenaria do município de Ourinhos (SP), identificam-se deformações nas paredes internas e/ou externas que podem se desenvolver sem um local específico. Parecem bolhas que, em estágio mais avançado, apresentam total deslocamento do reboco, resultando em prejuízos financeiros, tendo em vista a necessidade de reformas. Parte-se do princípio de que o modelo caracterizado pelo planejamento inadequado de uso da terra ao longo do médio rio Paranapanema, onde se localizam parte das empresas que extraem areia para construção civil comercializada no município aludido, pode comprometer sua qualidade, manifestada no acúmulo de micro-organismos oriundos do despejo de esgoto in natura, entre outros, que podem ter relação direta com as deformações nas paredes mencionadas. Portanto, foram elaborados mapas do uso e da cobertura da terra das áreas de preservação permanente (APP) do médio rio Paranapanema em 1997 e 2012, utilizando produtos do sensoriamento remoto e técnicas de geoprocessamento. Essas APP exercem uma função de barreira, dificultando o transporte de sedimentos originados das áreas de montante, que chegue ao rio, o qual pode comprometer a qualidade da areia. Observou-se que a supressão da vegetação natural das APP no médio rio Paranapanema, em detrimento da implantação de áreas antrópicas, refletirá na qualidade da areia destinada a construção civil.
\end{abstract}

Palavras-chave: uso da terra, qualidade microbiológica da areia, sensoriamento remoto, geoprocessamento.

In the masonry houses located in the county of Ourinhos (SP), Brazil, it was identified deformities in internal and / or external walls, which can develop without a specific place. Its appearance is that of bubbles, that in a more advanced stage, have total displacement of the plaster, which results in financial losses in view of the need for rehabilitation works in the affected area. The assumption is that the model which is characterized as being inadequate planning of land use along the middle Paranapanema River, where are located the companies that extract sand for construction market in the aforementioned municipality, may compromise their quality, manifested in the accumulation micro-organisms derived from the disposal of sewage in natura that can be directly related to the deformation of the walls. Thus, it was developed maps of land use and coverage of permanent preservation areas (PPA) of the middle Paranapanema River in two periods: 1997/2012, using products of remote sensing and GIS techniques. These PPA exert a barrier function, which makes it difficult for the sediment supply originated from upstream areas reach the river, which can compromise the quality of the sand. Therefore, it was observed that the removal of the natural vegetation from the PPA in the middle Paranapanema River to give place to antropic areas will be reflected in the quality of the sand intended for construction.

Keywords: land use, microbiological quality of the sand, remote sensing, geoprocessing.

1 Agradecemos à Fundação de Amparo à Pesquisa do Estado de São Paulo (Fapesp) pelo financiamento da pesquisa (Processo 2011/22570-8). 


\section{INTRODUÇÃO}

O modelo capitalista, definido como produção e reprodução do capital, também chamado de produtivismo, tem como um dos marcos referenciais o processo de degradação da natureza, submetida a um processo de pilhagem, ou seja, apropriação de recursos naturais pertencentes à coletividade, conforme Thomaz Junior (2005), o qual também menciona que essa é:

A lógica que reduz o valor de uso à lógica da acumulação do valor, no capitalismo, sendo que, quanto mais crescem a competitividade e a concorrência intercapitalista, mais destruidoras são as consequências, principalmente quando se considera a força humana que trabalha e a degradação ambiental, que contempla por sua vez, a relação metabólica entre homem, tecnologia e natureza (p. 164).

Concomitante ao processo de apropriação da natureza, destaca-se a pressão sobre os ecossistemas, que tem gerado conflito em relação ao uso e ocupação em áreas que deveriam ser de preservação permanente, como ao longo dos cursos hídricos, áreas de topo, vertentes muito íngremes, entre outros. Abreu Junior et al. (2005, p. 392) explicam sobre os impactos negativos gerados pela ação antrópica em áreas urbanas:

Toda atividade do homem tem como consequência a produção de resíduos e a alteração do meio que o cerca. O desenvolvimento dos grandes centros urbanos tem conduzido a um aumento desordenado na geração de resíduos e a consequente poluição ambiental. As quantidades geradas são assustadoras, o que vem acelerando o ritmo de degradação dos recursos naturais. A redução dos impactos ambientais causados por esgotos, lixo urbano e efluentes industriais, certamente apresenta-se como um dos maiores desafios a serem enfrentados pelo homem no século XXI.

Em contrapartida, Ab'Saber (2006, p. 32) faz uma alusão sobre as implicações da atividade humana em áreas rurais em detrimento dos ecossistemas naturais:

Os impactos da agricultura sobre os ecossistemas naturais, organizados em mosaicos regionais, são muito mais drásticos e muitas vezes irreversíveis do que se possa imaginar. Nas áreas tropicais dotadas de florestas e savanas, desde há séculos eliminam-se coberturas arbóreas biodiversas e seus componentes vivos para se produzirem espaços agrários. A supressão das florestas para as grandes plantações de cana, café, soja ou pastos era tida como uma necessidade normal e habitual para a organização de espaços produtivos de alimentos e insumos agroindustriais.

Quando há supressão da vegetação natural em detrimento da implantação de áreas agrícolas, sem o manejo adequado, podem-se gerar quadros de degradação do solo e, consequentemente, dos recursos hídricos. Segundo Bertoni e Lombardi Neto (2012, p. 28), o estado de São Paulo perde anualmente, por erosão hídrica, "cerca de 130.000.000 toneladas de terra. Essa perda representa aproximadamente $25 \%$ da perda sofrida pelo Brasil inteiro". Desse modo, ressalta-se a importância da cobertura vegetal para conservação desse recurso, em especial contra a erosão. Destaca-se o fato de que essas partículas inicialmente desprendidas pelo splash, em conjunto com agrotóxicos, defensivos agrícolas, efluentes diversos, até mesmo metais pesados, serão transportadas e depositadas nos corpos hídricos, gerando comprometimento tanto dos ecossistemas aquáticos como para quem depende diretamente deles, além da qualidade da água e dos recursos minerais, como é o caso da areia utilizada na construção civil.

Desse modo, tanto o uso de áreas rurais como urbanas, a partir dos processos em vertente - em especial a erosão, acelerada ou natural -, contribuem para o transporte e deposição de materiais diversos nos corpos hídricos, resultando em alterações das características naturais. Os referidos materiais, transportados pela erosão, levam consigo elementos que caracterizam o histórico de ocupação e manejo, como os sedimentos oriundos de áreas de cultivo de cana-de-açúcar fertirrigada, que possuem um aporte maior de matéria orgânica e nitrato, bem como outros elementos utilizados na produção do álcool etílico, o que poderá resultar na eutrofização dos corpos hídricos.

Sendo assim, vale destacar os efeitos benéficos da cobertura vegetal:

a. proteção direta contra o impacto das gotas de chuva;

b. dispersão da água, interceptando-a e causando sua evaporação antes que atinja o solo;

c. decomposição das raízes das plantas que, formando canalículos no solo, aumentam a infiltração da água; 
d. melhoramento da estrutura do solo pela adição da matéria orgânica, aumentando, assim, sua capacidade de retenção de água;

e. diminuição da velocidade de escoamento da enxurrada pelo aumento do atrito na superfície (BERTONI; LOMBARDI NETO, 2012, p. 59).

Desse modo, é notória a importância da cobertura vegetal e, de maior interesse neste trabalho, das áreas de preservação permanente (APP) ao longo dos cursos hídricos, tendo em vista o fato de serem responsáveis por conservar a água, proteger o solo, regular o volume das nascentes, fornecerem áreas de recreação, além de se constituírem como o ambiente adequado à fauna. Conforme a Food and Agriculture Organization of the United Nations (1993, p. 273, tradução nossa), "o uso do solo diz respeito à finalidade para a qual a terra é usada pela população humana local e pode ser definida como as atividades humanas que estão diretamente relacionadas a terra, fazendo uso de seus recursos ou tendo impacto sobre eles".

O uso da terra, entre as várias definições existentes, é geralmente associado às atividades conduzidas pelo homem relacionadas a uma extensão de terra ou a um ecossistema. De acordo com o Instituto Brasileiro de Geografia e Estatística (IBGE) (2013, p. 35), esse uso é "considerado como uma série de operações desenvolvidas pelos homens, com a intenção de obter produtos e benefícios, através do uso dos recursos da terra, ou seja, a atividade do homem que se acha diretamente relacionada a terra".

Ainda segundo o IBGE (2013), o uso da terra está relacionado à função socioeconômica da superfície básica, isto é, agropecuária, habitação e proteção ambiental. Dessa forma, entende-se a necessidade do monitoramento de seu uso por produtos do sensoriamento remoto e técnicas de geoprocessamento.

Dados de sensoriamento remoto, como fotografias aéreas e imagens de satélite, podem ser correlacionados à cobertura da terra e usados para mapear o tema. Entretanto, como o sensor remoto não registra a atividade diretamente, mas características da superfície da terra que retratam o revestimento do solo, as atividades de uso da terra correlacionadas à cobertura precisam ser interpretadas a partir de modelos, tonalidades, texturas, formas, arranjos espaciais das atividades e localização no terreno (IBGE, 2013).

\section{OBJETIVo}

Este artigo tem como objetivo compreender as consequências do uso da terra para a qualidade microbiológica da areia destinada à construção civil no município de Ourinhos (SP). Assim, parte-se do princípio de que o modelo caracterizado pelo planejamento inadequado de uso e cobertura da terra ao longo do médio rio Paranapanema, onde se encontram parte das empresas que extraem areia para construção civil comercializada em Ourinhos, pode comprometer a qualidade dela a partir do acúmulo de patógenos oriundos de esgoto clandestino, vinhoto, chorume, entre outros. Isso pode ter relação direta com as deformações nas paredes de boa parte das construções de alvenaria (FIGURA 1) do município. As deformações acarretam desvalorização do imóvel, além do comprometimento do orçamento familiar no que se refere às reformas necessárias por conta delas. Ademais, nota-se que a ausência de reformas periódicas pode ocasionar a evolução das deformações a rachaduras.

As deformações foram identificadas em 59\% das residências em dois bairros de Ourinhos, os quais foram fundados em diferentes períodos: Vila Sá, na década de 1930, e Jardim Brilhante, entre o final da década de 1980 e o início de 1990 (ABRANTES, 2014). No trabalho foi observado que as residências da Vila Sá, com mais de trinta anos de construção, em que foram realizadas reformas nos últimos vinte anos, passaram a apresentar deformações, visto que estas não eram presentes antes das reparações. Portanto, segundo Abrantes (2014), é possível inferir que o problema vai ao encontro do processo de expansão urbana e, consequentemente, do aumento da carga de dejetos nos corpos hídricos, em especial no rio Paranapanema, além disso, as margens dos rios passaram a ser mais ocupadas em relação ao período de formação da cidade, houve aumento e não tratamento dos efluentes domésticos, assim como a existência dos lançamentos clandestinos.

Outro fato que deve ser destacado consiste na localização dos portos de areia em Ourinhos, que se encontram predominantemente ao longo do curso do rio Paranapanema. Sendo assim, infere-se que a ausência de manutenção das matas ciliares remanescentes e a falta de recuperação, quando degradadas, irão certamente interferir negativamente na qualidade dos materiais extraídos do curso d'água. Essa afirmação baseia-se no fato de que essas matas ciliares exercem a função, que Tricart (1977) nomeia como "pente", ou seja, amortece a velocidade das partículas. Nesse sentido, o uso das geotecnologias é fundamental para o gerenciamento e monitoramento dessas áreas. 
Figura 1. Fases das deformações: (A) formação de bolhas; (B) bolhas estouradas; (C) deslocamento do reboco; e (D) rachaduras.
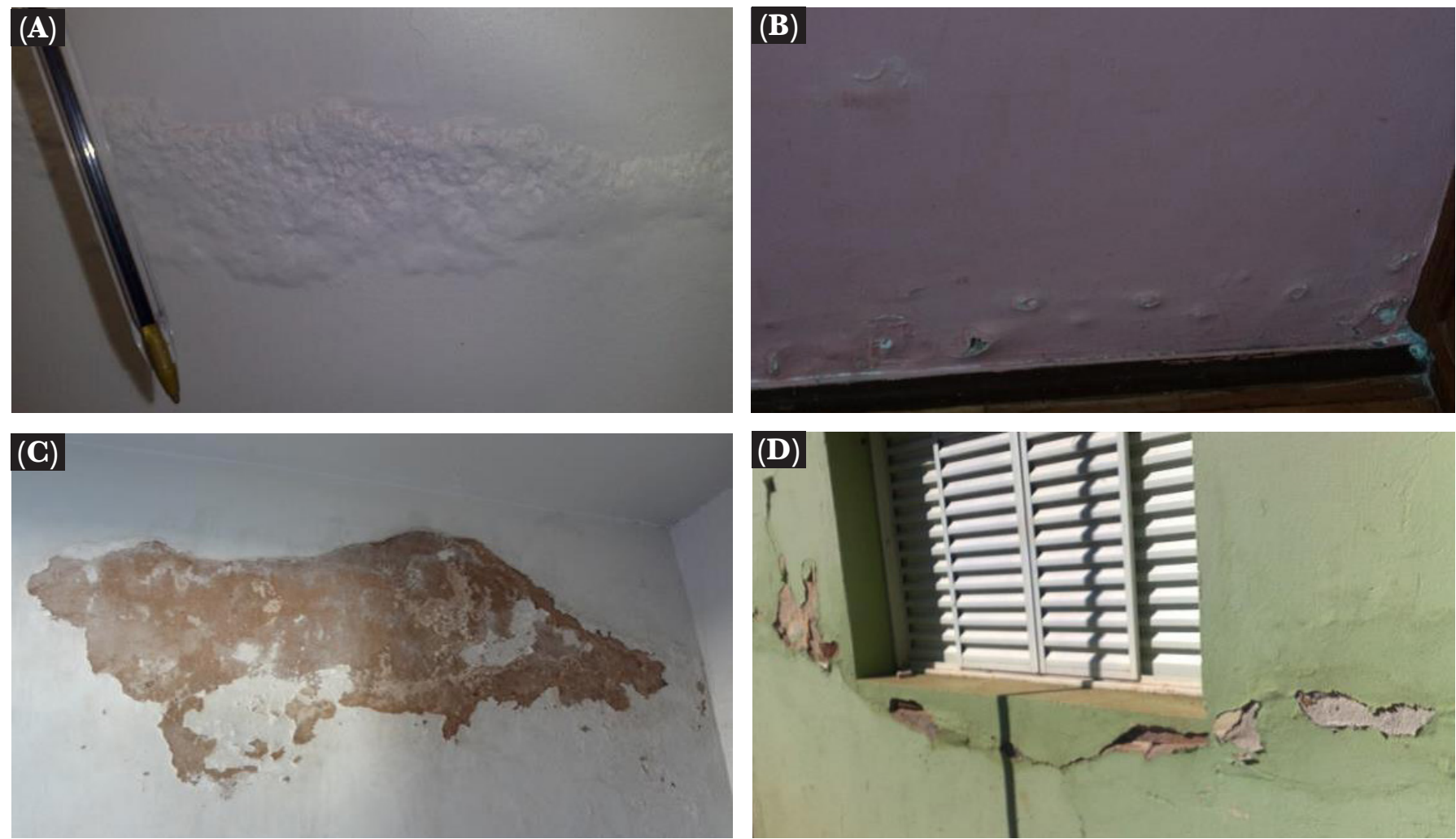

Fonte: Fotos de Abrantes (2014).

O USO DAS TÉCNICAS DE GEOPROCESSAMENTO NO MONITORAMENTO DAS ÁREAS DE PRESERVAÇÃO PERMANENTE (APP)

Os ambientes ditos naturais vêm sofrendo muitas alterações antrópicas. Com a introdução de novas tecnologias agrícolas e da expansão urbana, passam a produzir transformações na paisagem que, na maioria das vezes, podem ser prejudiciais, como erosão hídrica dos solos, movimentos de massa, enchentes, entre outras. Desse modo, o gerenciamento e monitoramento ambiental se tornam fundamentais para as unidades pesquisadas (SANTOS; PIROLI, 2012), o que acontece especialmente a partir do uso de geotecnologias.

Nesse sentido, trabalhar com geoinformação significa, antes de qualquer coisa, "utilizar computadores como instrumentos de representação de dados espacialmente referenciados. Deste modo, o problema fundamental da ciência da geoinformação é o estudo e a implementação de diferentes formas de representação computacional do espaço geográfico" (CÂMARA; DAVIS; MONTEIRO, 2004, p. 7). O geoprocessamento consiste em:
Um ramo da ciência que estuda o processamento de informações georreferenciadas utilizando aplicativos (normalmente SIGs), equipamentos (computadores e periféricos), dados de diversas fontes e profissionais especializados. Este conjunto deve permitir a manipulação, avaliação e geração de produtos (geralmente cartográficos), relacionados principalmente à localização de informações sobre a superfície da Terra (PIROLI, 2010, p. 5).

Dessa forma, com o desenvolvimento computacional, o geoprocessamento se tornou fundamental para organização, análise e cruzamento dessas informações, pois utiliza de técnicas matemáticas e computacionais para o tratamento da informação geográfica (CÂMARA; DAVIS; MONTEIRO, 2004). De acordo com os referidos autores, as ferramentas computacionais para o geoprocessamento, chamadas sistemas de informações geográficas (SIG), "permitem realizar análises complexas, ao integrar dados de diversas fontes e ao criar banco de dados georreferenciados. Tornam ainda possível automatizar a produção de documentos cartográficos" (CÂMARA; DAVIS; MONTEIRO, 2004, p. 2). 
Os SIG são aplicativos de computadores capazes de efetuar análises de informações geográficas e sua representação espacial. Assim, Fitz (2008, p. 23) define SIG como: "Um sistema constituído por um conjunto de programas computacionais, o qual integra dados, equipamentos e pessoas com o objetivo de coletar, armazenar, recuperar, manipular, visualizar e analisar dados espacialmente referenciados a um sistema de coordenadas conhecido".

Portanto, sempre que se perguntar "onde" haverá uma oportunidade para considerar a ação de um SIG (GÂMARA; DAVIS, 2001). Nesse âmbito, os SIG possuem três aplicações fundamentais na área geográfica, segundo Piroli (2010, p. 6), isto é, podem ser usados como:

a. ferramenta para a produção de mapas e ainda para geração e visualização de dados espaciais;

b. suporte para análise espacial de fenômenos e para a combinação de informações espaciais;

c. banco de dados geográficos, que têm funções de armazenamento e recuperação de informações espaciais.

As técnicas de geoprocessamento munidas pelos produtos do sensoriamento remoto constituem uma importante fonte de informação, além de produzir e obter novos dados. Assim, de acordo com Jensen (2009, p. 4):

Sensoriamento Remoto é o registro da informação das regiões do ultravioleta, visível, infravermelho e micro-ondas do espectro eletromagnético, sem contato, por meio de instrumentos tais como câmeras, escâneres, lasers, dispositivos lineares e/ou matriciais localizados em plataformas tais como aeronaves e satélites, e a análise de informação adquirida por meio visual ou processamento digital de imagens.

A vantagem de se usar produtos orbitais consiste na não perturbação por parte do sensor do objeto ou da área de interesse devido ao fato de não ser intrusivo quando está registrando passivamente a energia eletromagnética refletida ou emitida por um alvo ou fenômeno de interesse, isto é, a obtenção de dados se dá à distância, sem contato físico entre o sensor e a superfície terrestre (FLORENZANO, 2002).

Existem princípios fundamentais para interpretação de imagens do sensoriamento remoto, entre eles estão os elementos de interpretação de imagens, elencados por
Jensen (2009). Sendo assim, esses elementos incluem localização, tonalidade e cor, tamanho, forma, textura, padrão, sombra, altura e profundidade, volume, declividade, aspecto, sítio, situação e associação.

Os elementos de interpretação são de suma importância na identificação dos materiais superficiais, como vegetação, água e o solo descoberto, pois refletem diferentes porções de energia nas regiões do espectro eletromagnético do azul, verde, vermelho e infravermelho.

Além dos produtos do sensoriamento remoto, outra fonte de dados importante para o geoprocessamento consiste na cartografia digital, que compreende "os mapas e cartas topográficas, quando transformados em imagens, fornecem informações preciosas para o geoprocessamento. Normalmente, são usados como fonte de dados para o mesmo, e se beneficiam das informações geradas por este" (PIROLI, 2010, p. 7). Por ter grande eficiência em diagnósticos ambientais:

O geoprocessamento apresenta grande potencialidade no que se refere ao monitoramento dos problemas ambientais, permitindo a manipulação de diversos dados e informações e também a representação cartográfica destes [...]. Também tem colaborado na investigação da adequação do uso da terra, principalmente nas áreas de preservação permanente (APP), em função da importância destas para a preservação da biodiversidade (PIROLI, 2013, p. 28).

De acordo com Santos e Piroli (2012), a partir de produtos do sensoriamento remoto e técnicas de geoprocessamento foi verificada a substituição das matas ciliares por atividades agropastoris na calha principal do curso médio do rio Paranapanema, destacando, assim, o não cumprimento da legislação vigente e a falta de fiscalização, o que vai ao encontro com o quadro de degradação nas margens dos corpos d'água paulistas.

As áreas de preservação permanente, um dos focos deste trabalho, estão previstas no Código Florestal (BRASIL, 2012), como faixas de terra ocupadas ou não por vegetação nas margens de nascentes e olhos d'água, córregos, rios, lagos e lagoas, reservatórios artificiais, topo de morros, dunas, encostas, manguezais, bordas dos tabuleiros ou chapadas, restingas, áreas em altitude superior a $1.800 \mathrm{~m}$ e veredas. Para tanto, é necessário definir APP, segundo a legislação vigente:

Área protegida, coberta ou não por vegetação nativa, com a função ambiental de preservar os recursos hídricos, a 
paisagem, a estabilidade geológica e a biodiversidade, facilitar o fluxo gênico de fauna e flora, proteger o solo e assegurar o bem-estar das populações humanas (BRASIL, 2012).

Nesse sentido, no que se refere à delimitação das APP para as faixas marginais de qualquer curso d'água natural perene e intermitente, é estabelecida desde a borda da calha do leito regular (BRASIL, 2012).

Tanto as áreas que margeiam os cursos d'água como as que margeiam os recursos hídricos estáveis ou represados são comumente chamadas de matas ciliares. Abreu e Oliveira (2003, p. 1) entendem que mata ciliar é:

Aquela vegetação que se encontra nas margens dos cursos d'água formada por um conjunto de árvores, arbustos, cipós e flores. Essas áreas são de fundamental importância para o gerenciamento ambiental, pois além de contribuírem para a manutenção da qualidade dos recursos hídricos, funcionam como corredores úmidos entre as áreas agrícolas, favorecendo a proteção da vida silvestre.

Em consonância com Santos e Piroli (2012, p. 1604), "estas matas ciliares atuam como corredores para dissipação da fauna e flora e para conservação do ecossistema predominante na localização", além de que atuam como forma de minimizar os impactos negativos ao meio ambiente e à qualidade de vida humana. No que se refere ao papel do solo nas matas ciliares, Bigarella e Suguio (1990) afirmam que as matas ciliares auxiliam na infiltração da água da chuva difundindo o fluxo, além de impedirem, por meio da proteção física e estabilizadora de raízes e da interceptação de gotas de chuva pela folhagem, o impacto direto da água pluvial.

\section{Metodologia}

\section{Caracterização da área de estudo}

O município de Ourinhos, segundo o Instituto de Pesquisas Tecnológicas do Estado de São Paulo (IPT) (1981), encontra-se sobre o embasamento geológico do Grupo São Bento, Formação Serra Geral. Desse modo, os derrames basálticos da Formação Serra Geral, extensos e uniformes, ocorreram de acordo com o IPT (1981) no período entre 147 a 119 Ma passados, entretanto com maior frequência no intervalo de 130 a 120 Ma, caracterizado por extravasamento rápido de lava muito fluída em um processo contínuo de sistema de fraturas migratórias.
Portanto, geomorfologicamente o município paulista em estudo se localiza sobre a morfoescultura Planalto Ocidental Paulista, o qual ocupa a maior parte da Bacia Sedimentar do Paraná (ROSS; MOROZ, 1996). Sendo assim, suas formas de relevo se distinguem por serem colinas amplas e baixas de topos convexos, com declividade de 10 a $20 \%$, o que contribui em conjunto com o material parental (basalto) e os demais fatores para a formação do solo (clima, organismos e tempo), predominante do município, o latossolo vermelhoe, com menor expressividade, o nitossolo vermelho (EMBRAPA, 1999; OLIVEIRA et al., 1999). As referidas classes de solo, procedentes da Formação Serra Geral, são predominantemente argilosas, consequentemente, mais úmidas (devido aos microporos), acarretando um ambiente ideal para a permanência de fungos oriundos da matéria orgânica, o que pode agravar ou criar as condições necessárias para o desenvolvimento das deformações nas paredes das construções (ABRANTES, 2014).

Segundo a classificação climática de Köppen-Geiger, baseada em dados mensais pluviométricos e termométricos, o estado de São Paulo abrange sete tipos climáticos distintos, a maioria correspondente a clima úmido (CEPAGRI, 2016). Desse modo, o clima do município em estudo, de acordo com a referida classificação, é do tipo "Am", que caracteriza o clima tropical chuvoso, com inverno seco, em que o mês menos chuvoso tem precipitação inferior a $60 \mathrm{~m}$ e o mês mais frio com temperatura média superior a $18^{\circ} \mathrm{C}$.

No que se refere à hidrografia, o município de Ourinhos está inserido na vertente paulista da bacia hidrográfica do médio curso do rio Paranapanema, que pertence à região hidrográfica do Paraná, de acordo com a divisão hidrográfica do Brasil adotada pelo IBGE e pela Agência Nacional de Águas (SÃO PAULO, 2011).

Ourinhos pertence à Unidade de Gerenciamento de Recursos Hídricos - 17 (UGRHI-17): médio rio Paranapanema, a qual possui uma área de drenagem de $16.749 \mathrm{~km}^{2}$, com uma população de 660.475 habitantes (SÃO PAULO, 2011). Sendo assim, compõe o maior contingente populacional da vertente paulista da bacia hidrográfica do Paranapanema, cujos maiores núcleos urbanos são Assis e Ourinhos. Uma característica da UGRHI-17 é a forte expansão das lavouras de cana-de-açúcar e da indústria sucroalcooleira.

Diante do exposto, o rio Paranapanema e seus principais afluentes (Capivara, Novo, Pari, Pardo e Turvo), de interesse neste trabalho, compõem fontes de matéria-prima para portos de areia para a obtenção dos agregados 
miúdos da construção civil: areia e cascalho. Entretanto, os dois últimos passam por áreas urbanas, em sua maioria sem tratamento de esgoto e, consequentemente, há risco iminente de contaminação da areia.

Desse modo, observa-se que $75 \%$ dos municípios da UGRHI-17 coletam seus esgotos, exceto Salto Grande e Canitar (CBH-MP, 2007). Verifica-se que os municípios a montante de Ourinhos, como Canitar, Chavantes, Ipaussu, Manduri, Óleo e Águas de Santa Bárbara, não tratam seus esgotos domésticos. Portanto, esses efluentes possivelmente irão atingir as águas do Paranapanema na altura de, comprometendo a qualidade da água e, consequentemente, das matérias-primas que são extraídas do local, assim como suas aplicações e usos futuros.

Nesse contexto, é importante mencionar que Ourinhos possui duas lagoas de tratamento (decantação) de esgoto, uma às margens do rio Pardo e outra às margens do rio Paranapanema, no limite com Salto Grande. Entretanto, estão saturadas, além de que, por uma delas se localizar a jusante da coleta de água para abastecimento da população, o esgoto é despejado sem qualquer tratamento, não influenciando diretamente os moradores da cidade mencionada, mas indiretamente já que o esgoto ficará contido na barragem da usina hidrelétrica (UHE) em Salto Grande, a jusante de Ourinhos, comprometendo a qualidade da água do reservatório e da população que o usufrui.

Outra fonte provável de contaminação dos cursos hídricos e, consequentemente, da areia utilizada na construção civil, consiste ao aterro controlado de Ourinhos. De acordo com o Inventário estadual de resíduos sólidos domiciliares 2011 (SÃO PAULO, 2012), o índice de qualidade de aterro de resíduos sólidos é 3,6, enquadrando-se na avaliação de inadequado, a qual vai de 0 a 6 . Portanto, Ourinhos é o único da vertente paulista da bacia hidrográfica do rio Paranapanema que não apresenta destino adequado aos resíduos produzidos. Além da presença de matéria orgânica, a qual gera proliferação de determinadas bactérias e fungos que, quando presentes na areia usada na construção civil, ocasionam deformações nas paredes das casas e consequente prejuízo financeiro para os moradores (ABRANTES, 2014).

\section{Material e procedimentos metodológicos}

Para que as APP do curso principal do médio rio Paranapanema fossem estudadas detalhadamente, optou-se por adotar o sensoriamento remoto como fonte de dados e o geoprocessamento como base das técnicas utilizadas para análises e elaboração dos produtos oriundos delas.
No que se refere à área de abordagem, esta foi selecionada por ser um limite oficial estabelecido pelo Comitê de Bacias Hidrográficas do Médio Paranapanema que, no estado de São Paulo, é representado pela UGRHI-17. Entretanto, entende-se que os municípios que são margeados pelo rio Paranapanema, paulistas ou paranaenses, fazem uso de diferentes maneiras desse recurso natural. Sendo assim, a pesquisa sobre o uso e a ocupação das APP do médio rio Paranapanema não deveria ficar restrita apenas à margem paulista, mas abrange também a paranaense, respeitando o limite da UGRHI-17 em sua calha principal de drenagem.

Com a finalidade de acompanhar a ocupação da APP do médio rio Paranapanema nos últimos quinze anos, foi necessário gerar materiais cartográficos para observar as alterações sofridas nessas áreas a fim de inferir qual é a possível relação com a qualidade da areia destinada à construção civil de Ourinhos.

Assim, o procedimento adotado foi adquirir imagens orbitais referentes à área de estudo e cartas topográficas de 1970 com escala 1:50.000 dos municípios: Paranagi e Jacarezinho, no Paraná, e de Florínea, Cândido Mota, Ipaussu, Ourinhos, Cerqueira Cezar, Santa Cruz do Rio Pardo e Palmital, em São Paulo. No SIG ArcGis 9.3.1, foi realizado o georreferenciamento das cartas, no qual foi adotada a projeção Universal Transversa de Mercator e, como sistema de referência, o Datum Córrego Alegre. É importante mencionar que o ato de georreferenciar compreende a transformação geométrica que relaciona coordenada de imagem (linha, coluna) com coordenada de um sistema de referência. A georreferência foi calculada pela definição de pontos de controle no terreno, que permite o cálculo da relação entre os dois sistemas de coordenadas, os referidos pontos devem ser reconhecíveis tanto na imagem a ser georreferenciada quanto no mapa ou carta que contém o sistema de coordenadas a ser usado. A partir das cartas georreferenciadas pelos pontos de controle no terreno, foi feita a georreferência das imagens de satélite pelo mesmo método, no qual, para elaboração do mapa de uso da terra de 1997, foram georreferenciadas as duas cenas do satélite Landsat 5 correspondentes à área de estudo. $\mathrm{O}$ mesmo procedimento foi adotado para a georreferência das imagens do satélite Resourcesat-1.

Com esse material em mãos, foi feito um polígono da calha principal do curso médio do rio Paranapanema, cujos limites foram definidos por um shape das UGRHI do estado de São Paulo. Vale ressaltar que foi feito um polígono para cada um dos recortes temporais, pois nesse 
intervalo de tempo foram construídas novas represas na área, sendo assim o curso do rio em estudo foi modificado.

A próxima etapa foi a delimitação das APP da calha principal do curso médio do rio Paranapanema, que foram demarcadas a partir da geração de medidores de distâncias: buffers, gerados a partir do polígono feito na etapa anterior, com $100 \mathrm{~m}$, de acordo com a legislação vigente (BRASIL, 2012). Entretanto, foi realizado um buffer com $1 \mathrm{~km}$ para poder observar o avanço das atividades agropastoris sobre as APP e, a partir desse avanço, foi feito um recorte da área.

Com esse novo raster, iniciou-se a classificação, a qual é feita a partir da associação de pixels da imagem a um conjunto de rótulos que descrevam a característica real predominante de cada pixel (vegetação, água, solo etc.). Sendo assim, a classificação do raster foi feita pela classificação supervisionada, a qual é elaborada a partir da intervenção do profissional usando sua capacidade interpretativa.

As áreas de treinamento foram delimitadas de acordo com os usos identificados na imagem: solo exposto claro, médio e escuro; cultivo claro, médio e escuro; vegetação natural clara e escura; água clara e escura. É importante frisar que as áreas antrópicas não agrícolas não foram computadas devido a seus diferentes níveis de refletância, por isso foram criados polígonos, os quais serão sobrepostos à imagem gerada após classificação para que a delimitação fique mais próxima da área real.

Após identificar esses dez usos na imagem, criaram-se as assinaturas e depois foi aplicado o método da máxima verossimilhança por meio de uma ferramenta do ArcGis. No método da máxima verossimilhança, os valores de refletância de uma área de treinamento são descritos por uma função de densidade de probabilidade, baseada na estatística bayesiana. Segundo Piroli (2010, p. 39), "este classificador verifica a probabilidade que um pixel tem de pertencer a uma determinada classe e o classifica na categoria que tiver maior probabilidade". Por fim, foram reclassificadas de acordo com as classes descritas no Manual técnico de uso da terra (IBGE, 2013).

De acordo com o manual mencionado (IBGE, 2013), a nomenclatura para o levantamento do uso e da cobertura da terra apresentado foi organizada segundo três níveis hierárquicos, comportando desdobramentos para níveis de maior detalhe dependendo da escala de trabalho. Como a área da pesquisa era muito extensa e a resolução espacial das imagens orbitais utilizadas era baixa, optaram-se para aplicação das classes na pesquisa, conforme o Quadro 1:

Quadro 1. Definições da nomenclatura utilizada na classificação.

\begin{tabular}{|l|l|}
\hline $\begin{array}{l}\text { Áreas antrópicas } \\
\text { não agrícolas }\end{array}$ & $\begin{array}{l}\text { Estão associados todos os tipos de uso da terra de natureza não agrícola, como: áreas } \\
\text { urbanizadas, industriais, comerciais, redes de comunicação e áreas de extração mineral. }\end{array}$ \\
\hline $\begin{array}{l}\text { Áreas antrópicas } \\
\text { agrícolas }\end{array}$ & $\begin{array}{l}\text { Terra utilizada para a produção de alimentos, fibras e outras commodities do agronegócio. } \\
\text { Inclui todas as terras cultivadas, caracterizadas pelo delineamento de áreas cultivadas ou } \\
\text { em descanso, podendo também compreender áreas alagadas. Podem se constituir em zonas } \\
\text { agrícolas heterogêneas ou representar extensas áreas de plantations. Encontram-se inseridas } \\
\text { nesta categoria: lavouras temporárias e permanentes, pastagens plantadas e silvicultura. }\end{array}$ \\
\hline $\begin{array}{l}\text { Áreas de vegetação } \\
\text { natural }\end{array}$ & $\begin{array}{l}\text { Compreende um conjunto de estruturas florestal e campestre, abrangendo desde florestas e } \\
\text { campos originais (primários) e alterados até formações florestais espontâneas secundárias, } \\
\text { arbustivas, herbáceas e/ou gramíneo-lenhosas, em diversos estágios sucessionais de } \\
\text { desenvolvimento, distribuídos por diferentes ambientes e situações geográficas. }\end{array}$ \\
\hline Águas & $\begin{array}{l}\text { Incluem todas as classes de águas interiores e costeiras, como cursos d'água e canais (rios, } \\
\text { riachos, canais e outros corpos d'água lineares), corpos d'água naturalmente fechados, sem } \\
\text { movimento (lagos naturais regulados) e reservatórios artificiais (represamentos artificiais } \\
\text { d'água construídos para irrigação, controle de enchentes, fornecimento de água e geração de } \\
\text { energia elétrica), além das lagoas costeiras ou lagunas, estuários e baías. }\end{array}$ \\
\hline
\end{tabular}

Fonte: IBGE (2013).

A partir dessa nomenclatura, foi estabelecida a legenda dos mapas de acordo com as classes da cobertura e uso da terra. Por fim, a última etapa realizada na elaboração dos mapas foi a edição de seus leiautes.

Além dos produtos cartográficos, foi gerado também um banco de dados com as áreas em hectares de cada uma das classes mencionadas, o qual possibilitou a geração de gráficos e tabelas visando comparar as alterações sofridas nas APP no intervalo de tempo em estudo.

Após a classificação feita, foi-se a campo, munido das coordenadas, a fim de comprovar a existência ou não de áreas antrópicas não agrícolas em áreas de preservação permanente. A escolha do local se deu em vista do fato de ser uma grande área classificada como 
área antrópica não agrícola, próxima à barragem no município de Salto Grande.

Por fim, serão comparados com os resultados obtidos por Abrantes (2014) quanto à presença de matéria orgânica na areia destinada à construção civil comercializada em Ourinhos, a qual está no limite estabelecido pela Pormin (BRASIL, 2013) para ser considerada como substância deletéria e, assim, comprometer a qualidade dela.

\section{RESUltados E Discussão}

As duas áreas em destaque no mapa de uso da terra em APP do médio rio Paranapanema em 1997
(FIGURA 2) consistem nas maiores áreas antrópicas não agrícolas, onde está localizada a área urbana de Salto Grande, o qual tem 8.787 habitantes, segundo o Censo de 2010 (IBGE, 2010), concentrados às margens da represa da UHE (FIGURA 3). Na quadrícula 1 em destaque, o tipo de ocupação são chácaras para lazer onde, normalmente, o esgoto doméstico é lançado diretamente no curso hídrico ou em fossas negras.

A presença de áreas antrópicas, sejam agrícolas ou não agrícolas em detrimento da área de vegetação natural nas APP em 1997, mostra o descumprimento da legislação vigente. Além de comprometer a qualidade do curso hídrico, também afeta a qualidade dos recursos minerais extraídos dele, como é o caso da areia utilizada na construção civil.

Figura 2. Mapa de uso da terra em APP do médio rio Paranapanema em 1997.

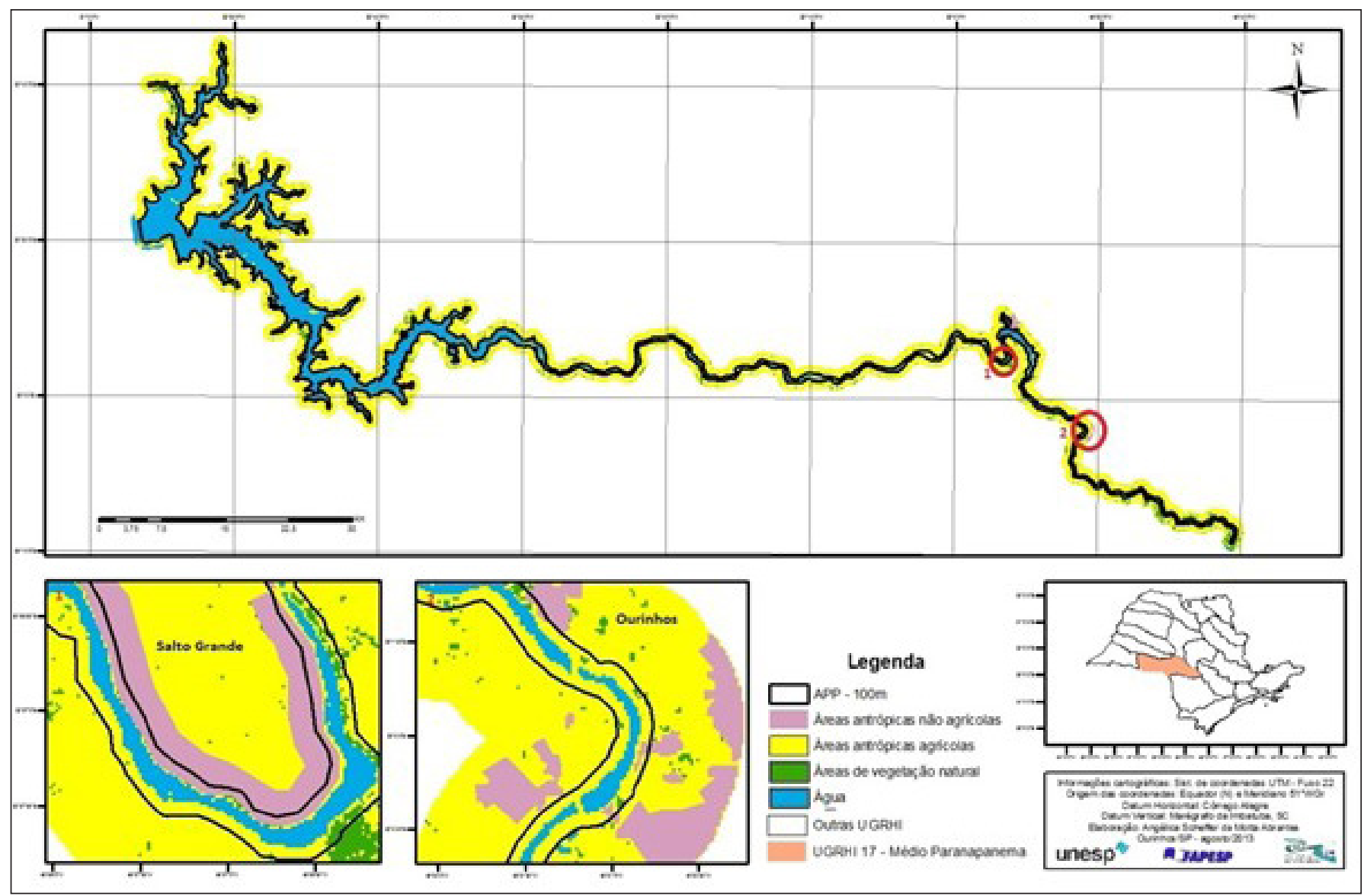

Fonte: Elaborado por Abrantes (2014). 
Figura 3. Represa da UHE em Salto Grande (SP), com destaque para os usos e ocupações das APP da represa: urbanização e ausência da mata ciliar.

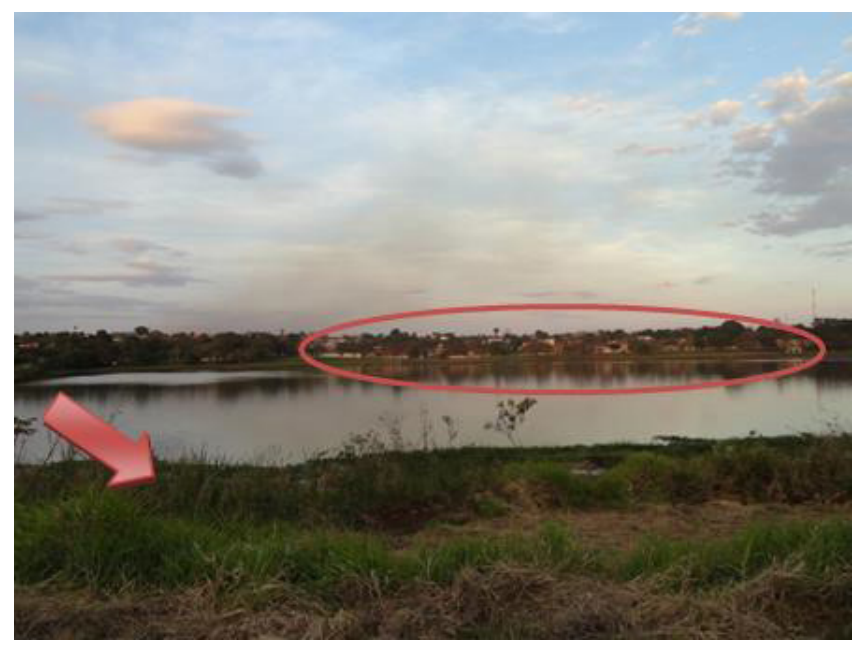

Fonte: Foto de Abrantes (2014).

Dessa forma, a partir dos mapas e do banco de dados, foi possível calcular a área em hectares de cada uma das classes de uso da terra (TABELA 1). Observase também que nesse período havia apenas a UHE de Salto Grande no curso médio do Rio Paranapanema. No que se refere apenas aos usos da APP, nota-se que: $1,2 \%$ correspondem à área antrópica não agrícola; $92 \%$ à área antrópica agrícola; e apenas $6,8 \%$ à área de vegetação natural.

Tabela 1. Áreas em hectare das classes de uso da terra em APP em 1997.

\begin{tabular}{lcc}
\hline \multicolumn{3}{c}{$\mathbf{1 9 9 7}$} \\
\hline Classes & Área (ha) & $\mathbf{( \% )}$ \\
Área antrópica agrícola & 109,51 & 1,2 \\
Área antrópica não agrícola & 8173,01 & 92 \\
Área de vegetação natural & 608,67 & 6,8 \\
Total & 8891,19 & 100 \\
\hline
\end{tabular}

O alto índice de área antrópica agrícola remete ao modelo tradicional de preparar o solo, o qual é caracterizado por retirar a cobertura vegetal, uso exacerbado de agrotóxicos, defensivos agrícolas e intensa mobilização. Dessa forma, a terra fica exposta aos processos erosivos, o que resultará em assoreamento dos cursos hídricos. Em conjunto com esses sedimentos, são carreados insumos agrícolas e matéria orgânica, os quais poderão comprometer a qualidade dos recursos minerais.

A partir do mapa de uso da terra em APP da calha principal do médio rio Paranapanema em 2012
(FIGURA 4), pode-se observar que aumentaram o número de barragens, pois foram construídas: UHE Ourinhos, concluída em 2005, localizada entre Ourinhos (SP) e Jacarezinho (PR); Canoas 1, de 1999, entre Candido Mota (SP) e Itambaracá(PR); e Canoas 2, de 1999, entre Palmital (SP) e Andirá (PR).

Foram mantidas as duas áreas em destaque no mapa de 2012 com intuito de mostrar o avanço da área antrópica não agrícola em Ourinhos (quadrícula 2) em direção às APP, como também a permanência da mesma área em Salto Grande. Desse modo, pode-se observar o descumprimento da legislação vigente.

Durante um trabalho de campo, foi percorrida toda a faixa referente à área antrópica não agrícola na quadrícula 1 em destaque, referente ao município de Salto Grande. Constatou-se o uso e ocupação indevida da APP, pois toda essa área é dividida em mais de 170 de propriedades particulares, como pode ser observado na Figura 5.

As referidas ocupações têm relação direta com a qualidade da areia, pois nas propriedades visitadas foi possível observar que o esgoto doméstico era despejado diretamente no curso hídrico, como também os sedimentos oriundos da remoção da mata ciliar, resultando em assoreamento de suas margens.

A partir do banco de dados gerado das áreas (em hectare) das classes de uso da terra em APP de 2012, observou-se que a área antrópica agrícola continua sendo o maior uso da APP (TABELA 2), a qual corresponde a 63\%: 1\% de área antrópica não agrícola e 36\% de vegetação natural.

Tabela 2. Áreas em hectare das classes de uso da terra em APP em 2012.

\begin{tabular}{lcc}
\hline \multicolumn{2}{c}{$\mathbf{2 0 1 2}$} & \\
\hline Classes & Área (ha) & \% \\
Área antrópica agrícola & $25.717,6$ & 63 \\
Área antrópica não agrícola & $8.695,83$ & 1 \\
Área de vegetação natural & $4.944,12$ & 36 \\
Total & $39.234,36$ & 100 \\
\hline
\end{tabular}

Sendo assim, pode-se traçar um comparativo entre o recorte temporal em estudo. Somando-se a área do rio Paranapanema em seu curso médio com as APP, houve aumento da área inundada de 112,16 km², de 1997 (cuja área era de 280,18 km²) para $2012\left(392,34 \mathrm{~km}^{2}\right)$, o qual se deve às novas barragens construídas no curso hídrico nesse intervalo de tempo. Isso se dá porque a área referente ao curso médio do rio Paranapanema em 1997 era de 191,27 km², e em 2012, 254,74 km². 
Figura 4. Mapa de uso da terra em APP do médio rio Paranapanema (2012).

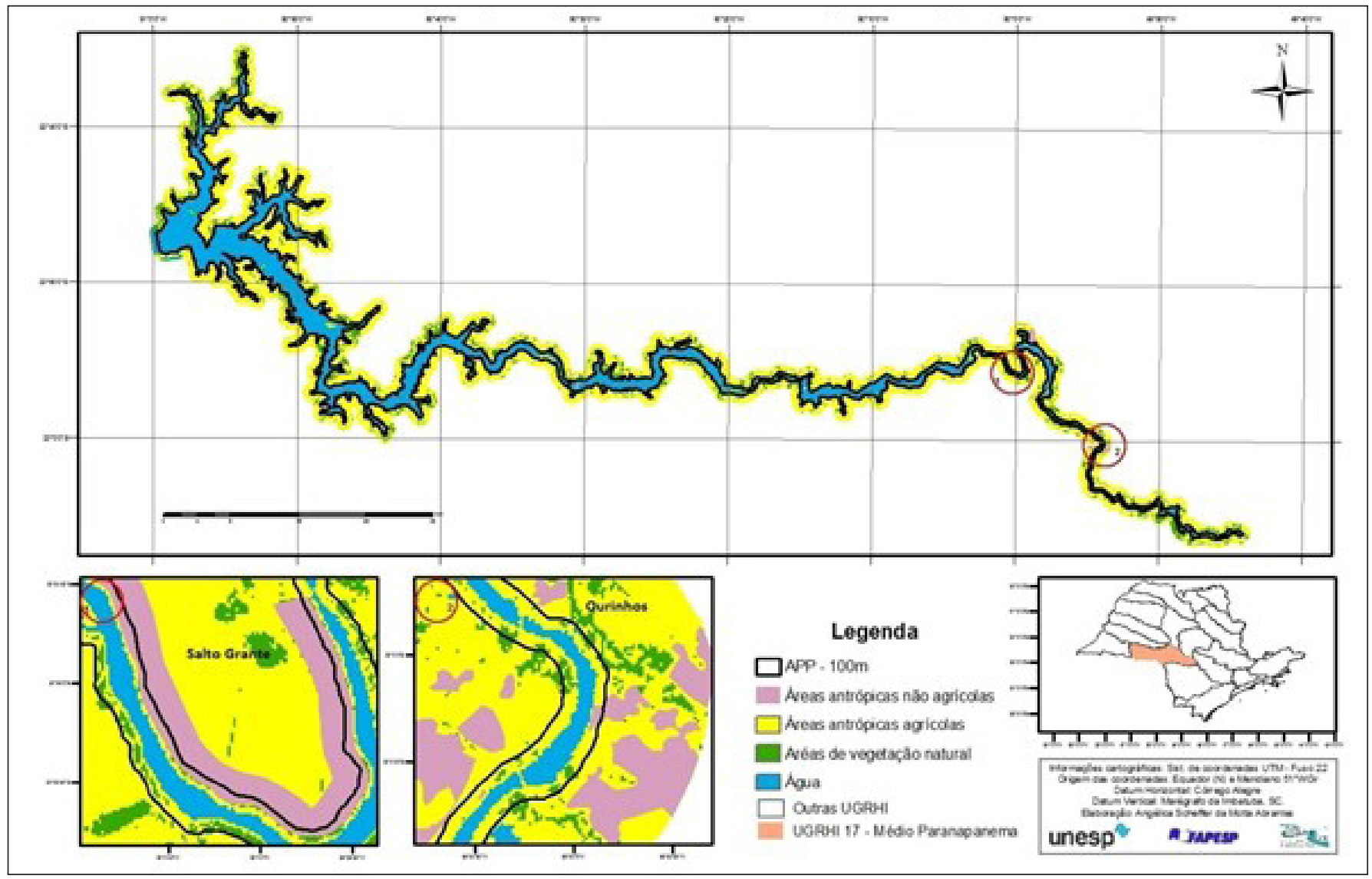

Fonte: Elaborado por Abrantes (2013).

Figura 5. Margem esquerda (A) e direta (B), respectivamente do trecho do rio Paranapanema em Salto Grande (SP), com destaque para os usos de lazer nas APP.
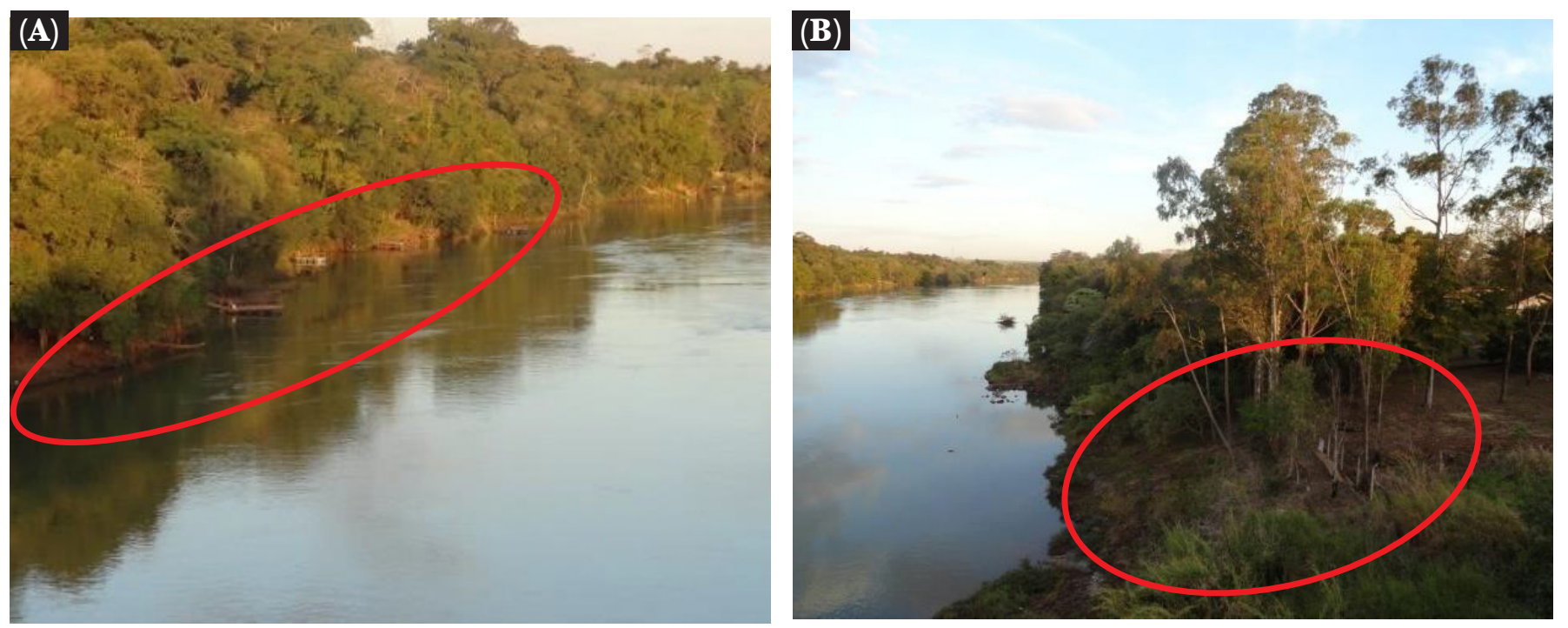

Fonte: Fotos de Abrantes (2014). 
Quanto às classes de uso da terra em APP no médio rio Paranapanema, observa-se aumento em todas as classes (GRÁFICO 1). O aumento da área de vegetação natural no recorte temporal em estudo é resultado, provavelmente, da política de compensação ambiental que as novas UHE devem cumprir ao se instalarem em um curso hídrico.

As deformações no reboco das paredes das casas de Vila Sá e Jardim Brilhante, bairros de Ourinhos, são resultado da presença de matéria orgânica, conforme afirma Abrantes (2014), isto é, fungos decompositores na areia destinada à construção civil, reflexo do uso e ocupação da terra das áreas adjacentes e do uso indiscriminado dos recursos naturais, como o solo e a água. Nesses usos, destaca-se o cultivo de cana-de-açúcar fertirrigada em conjunto com o destino inadequado de esgoto e lixo dos municípios da UGRHI-17, o que fará que, em conjunto com os processos em vertente e pela supressão da vegetação natural nas margens dos cursos d'água, o material transportado seja depositado nas calhas dos rios enriquecido com matéria orgânica, o que proporcionará um ambiente adequado para a proliferação de fungos decompositores, o que comprometerá a qualidade da areia destinada à construção civil.

Por fim, destaca-se a importância dos produtos do sensoriamento remoto e das técnicas do geoprocessamento para identificar os usos da terra em diferentes espaços temporais e, assim, a partir do banco de dados gerado, traçar comparações das mudanças dos referidos usos e, consequentemente, auxiliar na compreensão do cenário atual.

Gráfico 1. Gráfico comparativo das classes de usos da terra em APP na calha principal do médio rio Paranapanema entre 1997 e 2012.

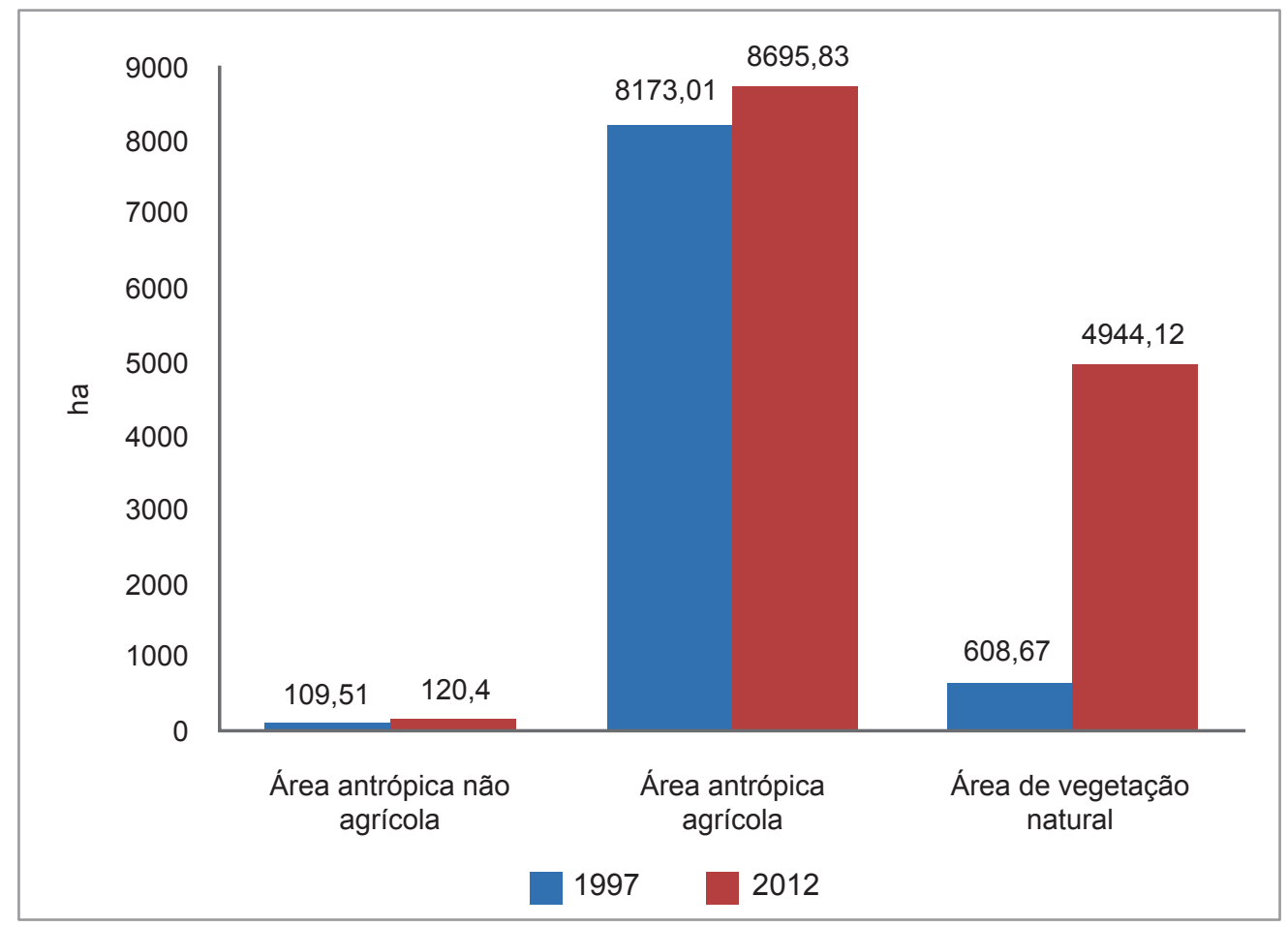

Fonte: Elaboração própria. 


\section{ConsideraÇÕES FINAIS}

A dragagem de recursos minerais para a construção civil, neste caso a areia, desencadeia uma série de impactos ambientais caso não seja planejada corretamente, como destruição da mata ciliar, ruídos, vibração, tráfego intenso e assoreamento de corpos d'água.

APP exerce um papel importante na qualidade da areia, pois filtrará ou barrará os materiais até que cheguem ao corpo hídrico, como o grande volume de sedimentos transportados pela erosão hídrica, que contêm insumos agrícolas, por exemplo, o que poderá ser um dos fatores responsáveis por afetar a qualidade desse material.

A constatação do aumento da área de vegetação natural no recorte temporal em estudo é resultado, possivelmente, da política de compensação ambiental que as usinas hidrelétricas devem cumprir ao se instalarem em um trecho do rio, ou seja, um desses atos de compensação consiste no reflorestamento de suas margens.

Outra constatação obtida nesta pesquisa se refere ao aumento da área antrópica não agrícola ao longo das APP na forma de ranchos, a qual pode ser interpretada como venda da paisagem natural após a construção das barragens.

Conclui-se também que o sensoriamento remoto e as técnicas de geoprocessamento são instrumentos importantes para o monitoramento das APP, compondo, assim, um forte aliado na tomada de decisões e para fins de planejamento ambiental.

\section{REFERÊNCIAS}

AB'SABER, A. N. Bases conceptuais e papel do conhecimento na previsão de impactos. In: PLATENBERG, C. M.; AB'SABER, A. N. (Orgs.). Previsão de impactos: o estudo de impacto ambiental no leste, oeste e sul - experiências no Brasil, na Rússia e na Alemanha. 2. ed. São Paulo: Edusp, 2006. p. 27-51.

ABRANTES, A. S. M. Identificação das possíveis causas e consequências do processo de deformações no reboco de algumas casas da Vila Sá e Jardim Brilhante, município de Ourinhos/SP. 2014. 10 f. Monografia (Trabalho de conclusão de curso em Geografia) - Universidade Estadual Paulista "Júlio de Mesquita Filho", Ourinhos, 2014.
ABREU, A. H.; OLIVEIRA, R. Regime jurídico das matas ciliares. Florianópolis: Ministério Público de Santa Catarina, 2003. Disponível em: < http://bit. ly/2sW7AlA>. Acesso em: 22 jun. 2017.

ABREU JUNIOR, G. H. et al. Uso agrícola de resíduos orgânicos potencialmente poluentes: propriedades químicas do solo e produção vegetal. In: SOCIEDADE BRASILEIRA DE GIÊNCIA DO SOLO. Tópicos em ciência do solo. Viçosa: Sociedade Brasileira de Ciência do Solo, 2005. v. 1, p. 391-470.

BERTONI, J.; LOMBARDI NETO, F. Conservação do solo. São Paulo: Ícone, 2012.

BIGARELLA, J. J.; SUGUIO, K. Ambientes fluviais. 2. ed. Florianópolis: UFPR, 1990.

BRASIL. Lei 12.651, de 25 de maio de 2012. Dispõe sobre a proteção da vegetação nativa; altera as Leis 6.938, de 31 de agosto de 1981, 9.393, de 19 de dezembro de 1996, e 11.428, de 22 de dezembro de 2006; revoga as Leis $\mathrm{n}^{\circ} 4.771$, de 15 de setembro de 1965, e 7.754, de 14 de abril de 1989, e a Medida Provisória n ${ }^{\circ} 2.166$ 67, de 24 de agosto de 2001; e dá outras providências. Diário Oficial da União, Brasília, DF, 28 maio 2012. Disponível em: <http://bit.ly/lzecGID>. Acesso em: 22 jun. 2017.

BRASIL. Ministério de Minas e Energia. Portal do Pequeno Produtor Mineral. Agregados minerais para construção civil: areia, brita e cascalho. Brasília, DF: Pormin, 2013. Disponível em: <https://goo.gl/vqQCqB> . Acesso em: 22 jul. 2013.

GÂMARA, G.; DAVIS, G. Introdução: por que geoprocessamento? In: CÂMARA, G.; DAVIS, C.; MONTEIRO, A. M. V. (Orgs.). Fundamentos de geoprocessamento. São José dos Campos: INPE, 2001. Disponível em: <https://goo.gl/E8QTvo>. Acesso em: 2 ago. 2013.

CÂMARA, G.; DAVIS, G.; MONTEIRO, A. M. V. (Orgs.). Introdução à ciência da geoinformação. São José dos Campos: Inpe, 2004. Disponível em: < http://bit. ly/2ftdAw6>. Acesso em: 22 jun. 2017.

CENTRO DE PESQUISAS METEOROLÓGICAS

E GLIMÁticas APLICADAS À 
AGRICULTURA - CEPAGRI. Clima dos municípios paulistas. Campinas: Unicamp, 2016. Disponível em: <http://bit.ly/2rHbpHD>. Acesso em: 22 jun. 2017.

GOMITÊ DE BAGIAS HIDROGRÁFICAS DO MÉDIO PARANAPANEMA - CBH-MP. Plano de bacia da unidade de gerenciamento de recursos hídricos do médio Paranapanema (UGRHI-17). São Paulo: CBH-MP, 2007. Caderno síntese.

EMPRESA BRASILEIRA DE PESQUISA AGROPECUÁRIA - EMBRAPA. Centro Nacional de Pesquisa de Solos. Sistema brasileiro de classificação de solos. Rio de Janeiro: Embrapa, 1999.

FITZ, P. R. Geoprocessamento sem complicação. São Paulo: Oficina de Textos, 2008.

FLORENZANO, T. G. Imagens de satélite para estudos ambientais. São Paulo: Oficina de Textos, 2002.

FOOD AND AGRICULTURE ORGANIZATION OF THE UNITED NATIONS. Agro-ecological assessments for national planning: the example of Kenya. Rome: FAO, 1993.

INSTITUTO BRASILEIRO DE GEOGRAFIA E ESTATÍSTICA - IBGE. Censo 2010. Rio de Janeiro: IBGE, 2010. Disponível em: <http://censo2010.ibge.gov. br/>. Acesso em: jun. 2013.

INSTITUTO BRASILEIRO DE GEOGRAFIA E ESTATÍSTICA - IBGE. Manual técnico de uso da terra. 3. ed. Rio de Janeiro: IBGE, 2013. Disponível em: <https://goo.gl/k3naWv>. Acesso em: jun. 2013.

INSTITUTO DE PESQUISAS TEGNOLÓGICAS DO ESTADO DE SÃO PAULO - IPT. Mapa geomorfológico do estado de São Paulo. São Paulo: IPT, 1981.
JENSEN, J. R. Sensoriamento remoto do ambiente: uma perspectiva em recursos terrestres. São José dos Campos: Parêntese, 2009.

OLIVEIRA, J. B. et al. Mapa pedológico do estado de São Paulo: legenda expandida. Campinas: Instituto Agronômico; Rio de Janeiro: Embrapa-Solos, 1999.

PIROLI, E. L. Introdução ao geoprocessamento. Ourinhos: Unesp, 2010.

Geoprocessamento aplicado ao estudo do uso da terra das áreas de preservação permanente dos corpos d'água da bacia hidrográfica do rio Pardo. 2013. 150 f. Tese (Livre-docência em Sensoriamento Remoto e Geoprocessamento) - Universidade Estadual Paulista "Júlio de Mesquita Filho", Ourinhos, 2013.

ROSS, J. L. S.; MOROZ, I. C. Mapa geomorfológico do estado de São Paulo. Revista do Departamento de Geografia, São Paulo, v. 10, p. 41-58, 1996.

Secretaria de Saneamento e Recursos Hídricos. Relatório de situação dos recursos hídricos do estado de São Paulo. São Paulo: SSRH, 2011.

Companhia Ambiental do Estado de São Paulo.

Inventário estadual de resíduos sólidos domiciliares 2011. São Paulo: Cetesb, 2012. Disponível em: <https://goo.gl/9Eeklf>. Acesso em: 20 ago. 2012.

SANTOS, V. R.; PIROLI, E. L. Monitoramento das áreas de preservação permanente (APPs) da calha principal do médio Paranapanema, apoiado em ferramentas de geoprocessamento. Revista Geonorte, Manaus, v. 3, n. 4, p. 1602-1611, 2012. Edição especial.

THOMAZ JUNIOR, A. Geografia passo a passo: ensaios críticos dos anos 90. Presidente Prudente: Centelha, 2005.

TRICART,J. Ecodinâmica. Rio de Janeiro: IBGE, 1977. 